\title{
Improvisation in the Design Classroom
}

NIDA ABDULLAH ${ }^{1}$ AND DENISE GONZALES CRISP ${ }^{2}$

1. Michigan State University, USA

2. North Carolina State University, USA

SUGGeSTED CITATION: Abdullah, N. \& Gonzales Crisp, D. “Improvisation in the Design Classroom.” Dialectic, 2.1

(2018): pgs. 10-17. DOI: http://dx.doi.org/10.3998/dialectic.14932326.0002.102

\section{Abstract}

This essay is a discourse on the value and benefits of utilizing improvisation, imbued with specific practices and rules, into design curricula as a means to:

- teach and model responsiveness within a given learning moment,

- facilitate students' interaction with the immediate social circumstances that contextualize a given design challenge, and

- prepare them to be ready for the uncertainties inherent in design processes.

The authors describe their version of an improvisational mindset, and present three classroombased scenarios that demonstrate ways in which improvisational thinking can alter design processes to shift student mindsets from the all-too-common "I must solve this problem so that it answers a specific question" approach to "We should construct something together and see what it tells us."

"Designing, if it is to survive as an activity through which we transform our lives, on earth and beyond, has itself to be redesigned, continuously."

John Chris Jones, in Designing Designing. London, UK: Architecture Design and Technology Press (Longman Group UK Limited): 1991, pgs. xi-xii. 


\section{Improvisation in the Design Classroom}

NIDA ABDULLAH \& DENISE GONZALES CRISP

Our roles as designers have become undeniably complex, as media is now vastly accessible through almost infinitely rich technological means. Most of the information we consume and help construct is in constant flux, changing and evolving from one moment to the next. Preparing design students to actively participate in such dynamic, systemically complex circumstances, much less to positively influence them, calls for pedagogic approaches and methods that achieve two primary goals. First, they must ensure that students learn to engage in responsive, flexible thinking that allows them to adjust to the moment; second, they must help students become reflective enough to handle interactions within evolving sets of social circumstances, so that they are ever ready for uncertainty.

This type of pedagogical thinking is described in the book A New Culture of Learning: Cultivating Imagination for a World of Constant Change, where Douglas Thomas and John Seely Brown liken culture to the matter that scientists grow in petri dishes under controlled conditions. The scientist does not interfere with the process because the very point of the experiment is to allow the culture - constrained and affected by the medium and environment - to uninhibitedly reproduce, "and then see what happens." Unlike the view of culture that seeks stability and adapts to change when forced, this perspective views culture as responding to its surroundings organically rather than trying to alter the circumstances as a response after the fact. In other words, culture thrives on change, and integrates change "as one of its environmental variables," which creates further change as situations and the circumstances that affect them morph and evolve over time. ${ }^{11}$

Thomas and Seely Brown propose play as a strategy for embracing and adapting to change, rather than attempting to grow from it. Implicit in this perspective, in terms of how it can be effectively applied to formulating and operating design pedagogy, is the active participation of students and teachers in the discovery of viable and innovative design possibilities while regularly forestalling the more formulaic problem-to-solution equation. In improvisation, all concerned parties involved in a given scenario have agency the freedom and expectation that anyone and everyone can affect how it evolves. All are engaged equally in the process. Judgement is suspended during the course of the exercise so that the gameplay can run its course organically.

\footnotetext{
Seely Brown, J., Thomas, D., A New Culture of Learning: Cultivating the imagination for a world of constant change. Charleston, SC, USA: CreateSpace Independent Publishing Platform, a DBA of On-Demand Publishing, LLC. 2011.
} 


\section{Improvisation as a Model for Play}

As design educators, we (the authors) have written exercises and delivered workshops that promote and model such improvisational values in the studio classroom. When people improvise, they respond to immediate circumstances spontaneously rather than attempt to alter them. Improvising involves free association, logic, and no small amount of imagination. These exercises invoke group improv performances, wherein players collaboratively construct unpredictable narratives guided by a set of constraints, or rules of play.

Three practices characterize group improvisation: 1) everyone participates; 2) everyone contributes; 3 ) everyone applauds, for themselves and for everyone else in the room, for any reason, and throughout a session ("high-fives" abound).

Everyone Participates: A group of people, such as students and their teachers, collectively participate in improvisational construction, each bringing his or her personal experience, physicality, knowledge, inclinations, imagination, and aspirations to the group production. The thing, or "moment," under construction would be quite different if even only one person were not to participate. Everyone in the group can make a viable contribution bringing little other than their own free associations, immediate responses, and consequent ideas.

Everyone Contributes: Improv performances are built from what is said and acted out moment-to-moment, under the single principle "the only wrong answer is no answer." To say or do nothing would be to disengage with the most important goal of group improvisation: together construct a thing that did not exist before. Active involvement without fear of "doing it wrong" deters the tendency to have second-thoughts when making decisions (which are ultimately ephemeral). Hesitation delays the improvised scene and suspends the play. And because each person contributes to the formation of a scene, each has a stake in the results. Individual investment for the good of the whole tethers everyone to the goal.
Everyone Applauds: All people in the process of learning, whether amongst others or individually with a tutor, perhaps even alone, are vulnerable to feelings of insecurity and rejection, especially in a social environment. Even a teacher, who facilitates but one small part of the learning process, is vulnerable. Everyone involved is required to support each other in order to avoid hesitation or being "wrong," and must work together towards a shared goal. The realization that all participants share in this vulnerability simultaneously helps to create the supportive environment that effective improv requires. The nearly constant applause that is central to much of improv practice - appreciative and supportive feedback - indirectly acknowledges the vulnerability inherent in social creation and learning, and it encourages participants to take risks. Positive audible and visible responsiveness between all participants is a means of recognizing and confirming everyone's courage as they openly participate and contribute to the outcome. This type of exchange is essential to helping individuals engaged in challenging learning processes to first embrace the personal and social discomfort in which they are immersed during a given moment, and then use it to empower their ability to think inventively in ways that they were too inhibited to consider before.

These three practices foster organic and energetic responses to many different types and sets of circumstances, including sensory stimuli, implied and expressed concepts, and individuated actions and statements - each of which is always present on the improv stage (as it is in life).

Improv "rules of play" guide the unscripted performance, and these relatively simple rules are easy to follow. Our three rules of play align with the founder of Improv $L A$ and “long form improv" master Keith Saltojanes' primary tenets, which state that the first rule of improvisation is to "Listen." 2 He teaches that one cannot respond to events occurring in a given moment if he or she is not paying attention. His second rule (more commonly considered the first rule of

\footnotetext{
2 Saltojanes, K. "Rules of Improv class lecture," Improv LA, May 15, 2011. Online. Available at: https://player.fm/series/improvla (Accessed June 11, 2017).
} 
improv) is "Say Yes...And." ${ }^{3}$ Players agree to agree with anything that other players state or perform, to accept statements and actions as true, and to add verbal details and physical deeds or gestures to whatever was initially stated or performed. Saltojanes' third rule is "Support." ${ }^{4}$ It argues that all players must receive the actions and statements of others as genius! (Applause!) Saltojanes' fourth rule is "Assume You Know:" 5 if, in a given scene, one player points to a tiger in the room, the other players must accept the idea that there is in fact a tiger in the room and assume that they know why it is there, or how it got there, no questions asked. Other players are not supposed to respond with a query like "How'd that tiger get in here?" Rather, a player might respond with something like, "I see you left the front door open, again." With these and Saltojanes' other rules of play in mind (i.e. "mistakes are invitations"), the players begin the performance by responding to a prompt of some sort - a word ("oatmeal"), a location ("the moon"), or perhaps a phrase ("sailors cooking dinner").

\section{Improvisation in the Design Classroom}

Our endeavor to bring improvisation into studio courses is manifested in a number of exercises and workshops that we write and conduct in our courses as design educators.These improvisational experiments exploit aspects of the theatrical improv ethos to expand student thinking and reveal design options during the ideation, iteration, and refinement phases of the design process. We will now discuss three of the workshops we have developed and tested in our undergraduate studio courses that make use of improv, as well as offer additional approaches to design pedagogy.

\section{The Improv Critique}

The Improv Critique is a means of bringing a given sampling of student work out from under the constraints imposed upon it by students' often limited perceptions of the possibilities - an initial narrow range of conventional ideas. Our goal is to help students discover more surprising and engaging design. Improv critique begins by forming students into groups of four or five. We ask each student to submit something they're currently working on, such as a logo iteration, a series of page spreads, or an interface screen. One by one, each student in the group presents the work to be "critiqued" on a table or a wall (print media), or full screen on a large display monitor (screen media). We have learned that, to aid focus, the work being discussed should be isolated from other visual stimuli that might distract attention, although attending to this is not crucial to the success of the exercise.

Recall that one of Saltojanes' primary rules of improv is to Listen to what is said by those around. Because this exercise also includes a visual component (the work), we add the rule "Look" at the artifact under discussion. The critique begins as one person in the group offers a concrete statement about what he or she reads, perceives, or observes in the work. He or she might state, "It's a lonely sky," or "The red is smiling," or "It's an upside-down coffee cup." Because the exercise asks students to enter into a wholly imaginative space of play, everything that is said initially is in fact true in that moment. Another person in the group then responds (again, while also looking at the work) with "Yes, and...," and adds a new bit of information, such as "Yes, and the sky is lonely because it has no clouds;" "Yes, and the red is smiling like a Cheshire cat;" "Yes, and coffee is spilled all over the table." Because every addition becomes true upon utterance, statements are spoken in the present tense. Additionally, students who try to plan what they will say instead of listening to the previous statement and building on it find that their contributions do not fit into the flow of the emerging narrative.

The improv critique continues in this manner with each student speaking one after the other, around and around within the group. Meanwhile, the person whose work is being "critiqued" writes down what he or she hears. The round is complete when either time is up (usually between five and ten minutes, depending on the complexity of the piece), or the round yields at least a dozen or more "Yes, ands." Upon completion of the improv critique, everyone applauds

$\begin{array}{ll}3 & \text { Ibid. } \\ 4 & \text { Ibid. } \\ 5 & \text { Ibid. }\end{array}$ 
(Applause!) before the group moves on to critique the next person's work.

Improvisation requires free and immediate associations, individual interpretation, and timely and responsive reactions to advance the narrative. We have found that design students sometimes have a difficult time making direct and imaginative statements in this context. They often start by describing the thing they're looking at literally ("It's red and green," "It's making use of a classical typeface," and so on). We have found that we need to prompt students to move beyond simple formal descriptions, encouraging them to freely interpret what they see and respond to what has been said. Students also initially tend to employ common “design speak," prefacing statements with tropes such as “I think it looks like...," "It feels like...," or "It reminds me of...." Such deferrals direct focus away from the work being discussed and prevent students from engaging in an exchange rooted in the all-important now. Students also typically begin with "Yes, but...," which implies rejection rather than acceptance of what is offered. so - "buts" are not allowed. Nor are "ifs." Only "Yes, and" can propel the critique into an unpredictable narrative.

Changing up the group members and running the exercise several times, perhaps with other artifacts that students are in the process of realizing, gives the students more material to work with and affords time for everyone to become comfortable with the practice in order to understand its potential for instigating lateral creative thinking.

\section{The "I Wish..." Critique}

The "I Wish..." Critique uses improv practices and rules to guide the iterative development of students' design work and help them expand the scope of their formal and conceptual ideas. This activity places students outside of project brief criteria (should these exist), and aims to interrupt both their self-imposed constraints, or those that have been inspired by language in the brief, or both. We have found that students who attempt to design work under these types of constraints can inhibit their own progress toward developing fresh (for them) ideas. As of this writing in January 2018, we have only tested this critique format at the point in the design process when a given project is nearing resolution, at least in the mind of the students who are anxious to complete a project.

To facilitate this type of critique, we separate students in the class into pairs, and then ask each student to present some part of his or her project for review by his or her partner. Paired students gather around a large piece of paper, such as butcher paper. Tracing paper, markers, scissors, adhesives, and other making materials are at the ready to facilitate quick ideation during the "I Wish..." Critique.

The pairs of students critique one student's work at a time. The student whose work is under review may take a brief minute or two to describe a particular aspect of or about his or her project, but long, drawn out defenses of the work are pointless in this exercise. The dialogue is prompted with the reviewer stating three "wishes" that he or she believes the work should fulfill in three successive rounds. The first of these wishes is practical: "I wish the letters were larger in scale." The second is arbitrary: "I wish the letters were reflective." The third is an absurd wish: "I wish the letters acted like kids jumping in a bounce house." In improv fashion, the student being critiqued cannot question or reject the reviewing student's wishes, but must accept them as points-of-fact that must be addressed. (Applause!) A student who express "wishes" likely has reasons for making particular wishes for a specific work, especially the practical one. However, the improv rule "Assume You Know" comes into play here, which means that the student whose work is under review accepts that the reasons and rationales that are guiding his or her partner's wishes are sound.

Once one student makes the first wish on behalf of his or her partner, both students set out to realize the wish through drawing, diagramming, illustrating, etc. using available materials. To visually manifest the wish, the partners build on each other's ideas in one or a series of connected visualizations. In this way, both students assume ownership 
of the work and together, enact the wish fulfillment with the butcher paper before them. Once a pair of students fulfills the three wishes for the first of their pair, they reverse roles and repeat the process for the second.

Following both the "Improv" and the "I Wish..." critiques, we ask students to quickly develop additional iterations, or to engage in further ideation, regarding a specific component of the project-in-progress (this sometimes occurs collaboratively, and other times occurs independently). Immediate return to the design allows students to apply to the work at hand concepts and ideas uncovered and/or invented during the critique, which effectively influences ensuing production. The visualized "wishes" serve as a document of the conversation as students proceed toward the final work. Students need not heed the wishes literally. Rather, the wishes and the ideas they spark are meant to encourage lateral thinking, to help students see their work in a fresh light and return to the full scope of the project with renewed energy.

\section{The “OK, GO!” Workshop}

The title of this workshop, “OK, GO!”, reflects its purpose: to jump-start ideation early in the students' design process with the aim of initiating concepts through visual exploration toward unforeseeable options. The first round of this workshop launches with two trigger questions: "What is it?" and "What is it not?" - the "it" being whatever students are working on to fulfill the parameters for a given project: a museum brand identity, for example. The students, teachers, and TAs (Teaching Assistants) who are participating in the workshop shout out anything that comes to mind that might be informed, at least in part, by their acquired knowledge about and lived experience with whatever is being designed. Someone then records the statements on a chalkboard or whiteboard: "It is free!:” "It is multifarious!," "It is not silent;" "It is not scary." Everyone in the room is called upon to contribute at least one word in response to each of the two trigger questions. The words need not be the truest, nor the most exact or accurate, but, once they have been stated and recorded as concepts, they become "fact for the moment," as improv rules dictate.
A second round of this workshop invites all of the participants to add a descriptive association as a phrase to the first round of statements and words to render each more concrete. For example: "It is free!” might be amended by “...like Harris Teeter TM sugar cookies,” or by “...like Wikipedia,” or by

“...like air." Any and all associations offered become valid and are written on the chalkboard or whiteboard. These phrases then serve as prompts for the ensuing "performance," which entails rapid image creation in a series of quick, five-minute rounds. Students sketch, draw, photograph, collage, construct, etc. using any media at hand and any digital software they have access to. In the first few rounds of these experiences, students create new images. In subsequent rounds, they build upon, add to, and/or manipulate selected images from previous rounds, applying the improv ethos of trying to add on to what has been posited previously as truths. These latter rounds are meant to evolve rather than to refine the images. Students end these processes by papering the walls of the classroom with all of the images they have produced. (Applause!) Together, the class identifies and discusses visual and conceptual patterns, triggers, and provocations as they affect and are affected by the project parameters.

In our experience, students, upon completing the "OK, GO!" workshops, begin the project with openness and concrete starting points. Students effectively triangulate their "improv" experiences and outcomes with their own hopes for the project, as well as with the project requirements. As creative individuals, design students naturally "put-two-andtwo-together" in order to make something that not only has not been made before, but that can also be considered good. When the whole class contributes to this goal together, the design work developed by each student with input from his or her peers is positively affected.

\section{Picking up threads}

The three exercises described in this article represent some of the many ways of introducing and then practicing the improvisational mindset into the design classroom. Improvisation is just one framework educators can use to teach students that uncertainty is an asset, and that responsiveness to 
change is an essential skill that enhances the design process. The beneficial outcomes of learning exercises like these, we speculate, make for more broad-minded design students who will carry such skills beyond the safe margins of the learning environment.

Pedagogical approaches using similar methods have been explored since at least the early 2oth century. Blueprint for Counter Education was conceived by Maurice Stein and Larry Miller and designed by Marshall Heinrichs (1970), and included three, folded $45^{\prime \prime} \times 37$ 1/4" posters plus a booklet entitled "Shooting Script." ${ }^{6}$ The publication served as a syllabus of sorts for a program of courses offered beginning in 1971 at the California Institute of the Arts (formerly the Chouinard Institute) in its Department of Critical Studies.

The posters were originally designed to function as "a portable learning environment for a new process-based model of education, and a bibliography and checklist that map [s] patterns and relationships between radical thought and artistic practices - from the avant-gardes [sic] to postmodernism." Although anchored in the philosophies and theories of Herbert Marcuse and Marshall McLuhan, the posters presented students with a wide range of discussion points and potential trajectories of study. Selecting as a starting point a theorist, philosopher, or concept from one of the posters is akin to picking up a prompt to initiate an improv scene. In use, Blueprint inspired what were called "wanderings." Students embarked on explorations that were "predicated on individual perceptions, relationships among participants, text and visual pairings, and the immediate environment in time (physical contexts)." In a word, improvisation. The fact that Blueprint was re-printed in 2016 suggests renewed interest in pedagogical and curricular reform in the process of adapting to diverse cultures that thrive on change. ${ }^{7}$

\footnotetext{
6 Stein, M, Miller, L., Heinrichs, M. Blueprint for Counter Education. New York, NY, USA: Doubleday, 1970.

7 Schnapp, J., Cronin, P., Michaels, A. Blueprint for Counter Education, Expanded Reprint New York, NY, USA: Inventory Press, 2016

8 Seely Brown, J., Thomas, D., A New Culture of Learning: Cultivating the imagination for a world of constant change. Charleston, SC, USA: CreateSpace Independent Publishing Platform, a DBA of On-Demand Publishing, LLC. 2011. Online. Available at: https://www. createspace.com/ (Accessed 2 April, 2018).
}

Inserting improv practices and rules of play into design (or any) pedagogy teaches students to appreciate and accept that which can be expressed and that can occur "in the moment." They also learn that this type of acceptance precludes judgement in this process. Improv practices are, by definition, social and collaborative, and, if the ground is well-prepared, lead to fertile environments for learning and creativity. Improv rules help to encourage participation and elicit responsiveness in any momentary design scenario. These rules exemplify the value of expanding and adding to the ideas of others while maintaining a focus on the larger goal of generating appropriate and surprising design rather than on boosting individual performance. The lessons of improvisation, as well as the experience of improvising, help shift the design mindset from "I must solve this problem" to "We must construct something together and see what it tells us." 8

Improv players are fond of prefacing performances with something along the lines of "This is the very first and very last time you will see this." What might happen if design educators were to attempt to guide their students through thinking and problem-solving processes wherein the principal ethos is exactly that? (Applause!)

\section{References}

Jones, J.C. Designing Designing. London, UK: Architecture Design and Technology Press (Longman Group UK Limited): 1991, pgs. xi-xii.

Saltojanes, K. "Rules of Improv class lecture," Improv LA, May

15, 2011. Online. Available at: https://player.fm/series/improvla (Accessed June 11, 2017).

Schnapp, J., Cronin, P., Michaels, A. Blueprint for Counter Education, Expanded Reprint. New York, NY, USA: Inventory Press, 2016.

Seely Brown, J., Thomas, D., A New Culture of Learning: Culti-vating the imagination for a world of constant change. Charleston, SC, USA: CreateSpace Independent Publishing Platform, a DBA of On-Demand Publishing, LLC. 2011. Online. 
Available at: https://www.createspace.com/ Accessed 2 April, 2018).

Stein, M, Miller, L., Heinrichs, M. Blueprint for Counter Education. New York, NY, USA: Doubleday, 1970.

Nida Abdullah is an Assistant Professor in the Department of Art, Art History and Design at Michigan State University. Prior to this appointment, she served as a Lecturer of Graphic Design at the Welch School of Art and Design in the College of Arts and Sciences at Georgia State University.

Her research explores communication and participation hierarchies in computer supported collaborative work (CSCW) processes and ad-hoc approaches as a model for design research, practice, and pedagogy. She has presented on Designing the Participatory Design Experience and contributed to Respectful Design: Decolonization as an Urgent Imperative. She has worked on projects with various cultural and educational institutions, including MASS MOCA, Project $M$ and Winterhouse, SomArts Cultural Center, the United Nations, UNOY, The Duke Center for Science Education, and the IEI Public Policy Institute. She holds a BGD and MGD from the College of Design at North Carolina State University.

Denise Gonzales Crisp is a graphic designer, writer, and professor of graphic design at North Carolina State University College of Design (since 2002), where she currently directs the graduate program. She holds an M.F.A. in graphic design from the California Institute of the Arts and a B.F.A. from Art Center College of Design.

She is author of Graphic Design in Context: Typography (Thames \& Hudson, 2011). She has been invited to speak at numerous conferences, universities, and events-at TYPO Talks, ATypl (Association Typographique Internationale/the International Typography Association) in 2009 (Mexico City), the Walker Art Center (Minneapolis), GraficEurope (Berlin),
RMIT (Melbourne), ArtCity (Calgary), among others. She has exhibited her work both nationally and internationally, and is published widely in design journals; among these are Émigré, Metropolis, Print, Graphis, Eye, Items, and KAK.

Gonzales Crisp was senior designer for the Art Center College of Design in Pasadena and principal of SuperStove!, a design studio focussed on designing "books for the cultural sector". She designed Utopian Entrepreneur by Brenda Laurel, part of the Mediawork pamphlet series for MIT Press, edited by Peter Lunenfeld on "the intersections of art, design, technology, and market culture."

Gonzales Crisp has taught graphic design at Art Center College of Design, CalArts, and the Otis Art Institute. She sits on the Executive Board of Design Inquiry, a non-profit educational organization devoted to researching design issues in intensive team-based gatherings, with (co-founder) Margo Halverson, (co-founder) Peter Hall, Emily Luce, Anita Cooney, Gabrielle Esperdy, Gail Swanlund, Joshua Singer, and Ben Van Dyke. 